\title{
CAPÍTULO 14: CARACTERIZAÇÃO FÍSICA E QUÍMICA DAS FOLHAS DE SERIGUELA PARA FINS DE USO EM DESENVOLVIMENTO DE NOVOS PRODUTOS ALIMENTÍCIOS
}

\section{CAPÍTULO 14: CARACTERIZACIÓN FÍSICA Y QUÍMICA DE LAS HOJAS DE SERIGUELA PARA SU USO EN DESARROLLO DE NUEVOS PRODUCTOS ALIMENTICIOS}

\section{CHAPTER 14: PHYSICAL AND CHEMICAL CHARACTERISATION OF SERIGUELA LEAVES FOR THE PURPOSE OF DEVELOPING NEW FOOD PRODUCTS}

\author{
Desirée Bridgitt de França Bernardo ${ }^{1}$; Wiliam Eugênio Lopes da Silva ${ }^{2}$; Maely Nunes Lopes ${ }^{3}$; Suzana Pedroza \\ da Silva ${ }^{4}$
}

DOI: $\underline{\text { https://doi.org/10.31692/978-65-88970-18-8.192-207 }}$

\begin{abstract}
RESUMO
A importância da ingestão de hortaliças na alimentação humana está inteiramente voltada para o campo nutricional, visto que este consumo se faz pela precisão de suprir as necessidades nutricionais do organismo, além das hortaliças folhosas existem as plantas alimentícias não convencionais (PANC) que são plantas ou partes de plantas (talos, cascas, folhas, sementes, flores) seguras e comestíveis, que não fazem parte dos hábitos alimentares humanos. Devido a versatilidade no preparo das hortaliças folhosas e das PANCs torna-se visível a possibilidade do desenvolvimento de novos produtos alimentícios. Para isto as análises físico-químicas de alimentos garantem um detalhamento completo da composição da matéria-prima para fins de pesquisas de novos produtos, fiscalização e controle de qualidade. O presente estudo teve como objetivo a caracterização física e química das folhas de seriguela para fins comestíveis, buscando melhores formas de consumo e possíveis aplicações em produtos alimentícios. As amostras foram coletadas na cidade de Lagoa do Ouro-PE e transportadas para a cidade de Garanhuns-PE em embalagem de polietileno à temperatura ambiente de aproximadamente $26^{\circ} \mathrm{C}$, em seguida foram lavadas com água corrente, secas com papel toalha e realizadas as análises físico-químicas de teor de umidade, teor de cinzas, cor, $\mathrm{pH}$, sólidos solúveis totais (SST), atividade de água (Aw), acidez total titulável (ATT), açúcares redutores e lipídeos. Os resultados obtidos foram teor de umidade $(30,34 \%)$, teor de cinzas $(3,51 \%)$, cor: luminosidade $\left(\mathrm{L}^{*}\right)(46,27)$, a* $(-12,33)$ e b* $(+29,80), \mathrm{pH}(2,39)$, sólidos solúveis totais $\left(9,73^{\circ}\right.$ Brix), atividade de água $(0,99$ aw), acidez total titulável $(0,13 \%)$, açúcares redutores $(0,835$ $\mathrm{g} / \mathrm{L})$ e lipídeos $(6,56 \%)$ que indicam, em sua maioria, parâmetros similares a outras PANCs e hortaliças folhosas comumente utilizadas na alimentação humana em sua forma crua ou em chás e sucos, firmando a possibilidade do uso das mesmas como ingredientes em produtos alimentícios como farinhas, doces, temperos, licores, saladas entre outros. Dessa forma, a caracterização física e química das folhas de seriguela comprovou que as análises de teor de cinzas, cor, atividade de água, acidez total titulável, açúcares redutores e lipídeos foram compatíveis com as características físico-químicas desejáveis para folhas, flores e hortaliças folhosas comestíveis, demonstrando ser uma alternativa viável e com grande potencial para o desenvolvimento de novos produtos alimentícios ou melhoramento de produtos já existentes no mercado.
\end{abstract}

Palavras-chave: Folhas de seriguela, Hortaliças, Inovação, Seriguela.

\footnotetext{
${ }^{1}$ Engenharia de Alimentos, Universidade Federal do Agreste de Pernambuco, desireebridgitt@ gmail.com ${ }^{2}$ Engenharia de Alimentos, Universidade Federal do Agreste de Pernambuco, william_739eugenio@ hotmail.com ${ }^{3}$ Engenharia de Alimentos, Universidade Federal do Agreste de Pernambuco, lopesmaely@gmail.com

${ }^{4}$ Doutora em Engenharia Química, Universidade do Agreste de Pernambuco, suzana.pedroza@ufape.edu.br
} 
La importancia de la ingesta de hortalizas en la alimentación humana está totalmente orientada hacia el campo nutricional, ya que este consumo se hace por la precisión de suplir las necesidades nutricionales del organismo, además de las hortalizas frondosas existen las plantas alimenticias no convencionales (PANC) que son plantas o partes de plantas (tallos, cáscaras, hojas, semillas, flores) seguras y comestibles, que no forman parte de los hábitos alimenticios humanos. Debido a la versatilidad en la preparación de las hortalizas frondosas y de los pancs se hace visible la posibilidad del desarrollo de nuevos productos alimenticios. Para ello, los análisis fisicoquímicos de alimentos garantizan un detalle completo de la composición de la materia prima para fines de investigación de nuevos productos, fiscalización y control de calidad. El presente estudio tuvo como objetivo la caracterización física y química de las hojas de seriguela para fines comestibles, buscando mejores formas de consumo y posibles aplicaciones en productos alimenticios. Las muestras fueron recogidas en la ciudad de Lagoa do Ouro-PE y transportadas a la ciudad de Garanhuns-PE en embalaje de polietileno a temperatura ambiente de aproximadamente $26^{\circ} \mathrm{C}$, luego fueron lavadas con agua corriente, secas con papel toalla y realizadas los análisis físico-productos químicos con contenido de humedad, contenido de cenizas, color, $\mathrm{pH}$, sólidos solubles totales (SST), actividad de agua (Aw), acidez total titulable (ATT), azúcares reductores y lípidos. Los resultados obtenidos fueron contenido de humedad (30,34\%), contenido de cenizas $(3,51 \%)$, color: luminosidad $\left(\mathrm{L}^{*}\right)(46,27), \mathrm{a}^{*}(-12,33)$ y b* $(+29,80), \mathrm{pH}(2,39)$, sólidos solubles totales $\left(9,73^{\circ} \mathrm{Brix}\right)$, actividad de agua $(0,99 \mathrm{aw})$, acidez total titulable $(0,13 \%)$, azúcares reductores $(0,835 \mathrm{~g} / \mathrm{L})$ y lípidos $(6,56 \%)$ que indican, en su mayoría, parámetros similares a otros pancs y hortalizas frondosas comúnmente utilizadas en la alimentación humana en su forma cruda o en tés y jugos, reafirmando la posibilidad del uso de las mismas como ingredientes en productos alimenticios como harinas, dulces, especias, licores, ensaladas entre otros. De este modo, la caracterización física y química de las hojas de seriguela demostró que los análisis de contenido de cenizas, color, actividad de agua, acidez total titulable, azúcares reductores y lípidos eran compatibles con las características fisicoquímicas deseables para las hojas, frondosas flores y hortalizas comestibles, demostrando ser una alternativa viable y con gran potencial para el desarrollo de nuevos productos alimenticios o mejora de productos ya existentes en el mercado.

Palabras clave: Hojas de seriguela, Hortalizas, Innovación, Seriguela.

\begin{abstract}
The importance of the intake of vegetables in the human diet is entirely focused on the nutritional field, since this consumption is made by the precision to meet the nutritional needs of the organism, In addition to leafy vegetables there are unconventional food plants (PANC) that are safe and edible plants or parts of plants (stalks, bark, leaves, seeds, flowers) that are not part of human eating habits. Due to the versatility in the preparation of leafy vegetables and Pancs, it is possible to develop new food products. For this, the physico-chemical analysis of food guarantees a complete detailing of the composition of the raw material for the purpose of researching new products, monitoring and quality control. The present study aimed at the physical and chemical characterization of the seriguela leaves for edible purposes, seeking better forms of consumption and possible applications in food products. The samples were collected in the city of Lagoa do Ouro-PE and transported to the city of Garanhuns-PE in polyethylene packaging at an ambient temperature of approximately $26^{\circ} \mathrm{C}$, then were washed with running water, dried with paper towels and performed the physical analysischemicals with moisture content, ash content, colour, $\mathrm{pH}$, total soluble solids (SST), water activity (Aw), titratable total acidity (ATT), reducing sugars and lipids. The results obtained were moisture content (30.34\%), ash content (3.51\%), color: luminosity $\left(\mathrm{L}^{*}\right)(46.27)$, $\mathrm{a}^{*}(-12.33)$ and $\mathrm{b}^{*}(+29.80), \mathrm{pH}(2.39)$, total soluble solids $\left(9.73{ }^{\circ}\right.$ Brix $)$, water activity $(0.99 \mathrm{aw})$, total titratable acidity $(0.13 \%)$, reducing sugars $(0.835 \mathrm{~g} / \mathrm{L})$ and lipids $(6.56 \%)$ which mostly indicate parameters similar to other Pancs and leafy vegetables commonly used in human food in their raw form or in teas and juices, confirming the possibility of using them as ingredients in food products such as flours, sweets, spices, liquors, salads among others. Thus, the physical and chemical characterization of the seriguela leaves proved that the analyses of ash content, color, water activity, total titratable acidity, reducing sugars and lipids were compatible with the desired physicochemical characteristics for leaves, edible leafy flowers and vegetables, demonstrating to be a viable alternative and with great potential for the development of new food products or improvement of existing products on the market.
\end{abstract}




\section{INTRODUÇÃO}

A alimentação é uma das mais básicas necessidades humanas, cujos hábitos contemporâneos começaram a ser estabelecidos na pré-história e sofreram adaptações com o passar do tempo. A alimentação, além de uma necessidade biológica, é também um grande sistema simbólico, cheio de significados sociais, religiosos, éticos e políticos. O alimento é apreendido, representado e nem tudo que é alimento é percebido como comestível (CARNEIRO, 2003; RAMALHO; SAUNDERS, 2000).

Grande parte da alimentação brasileira é composta por frutas, legumes e verduras, sendo um reflexo cultural da culinária africana trazida pelos negros durante a época de escravidão (DIAS et al., 2005; FREIRE, 1987). Entretanto, existem muitas espécies de hortaliças, partes de plantas e plantas alimentícias não convencionais (PANC) que são pouco exploradas na produção de alimentos e podem constituir uma alternativa de renda e de diversificação de novos produtos alimentícios. Essas espécies geralmente não fazem parte do cardápio e/ou do conhecimento do consumidor (ALMEIDA et al., 2014), como é o caso das folhas de seriguela.

Além dos frutos da serigueleira, as suas folhas, as sementes e as cascas também são comumente consumidas cruas ou aproveitadas em receitas de uso medicinal, principalmente pela população do interior da região Nordeste do Brasil, local de maior predominância desta planta. O consumo das partes da planta não é pertencente aos hábitos alimentares da população brasileira, entretanto seu uso não deixa de ser uma alternativa alimentar e/ou medicinal tradicional ou cultural de alguns povos.

Portanto, sendo as folhas de seriguela pouco conhecidas e estudadas, sua utilização exige pesquisas que identifiquem as suas melhores formas de consumo e as possíveis aplicações em produtos alimentícios, fazendo-se necessário, o detalhamento de sua composição físicoquímica. Diante do exposto, o presente estudo teve como objetivo a caracterização física e química das folhas de seriguela para fins comestíveis, de forma que seja adicionada e/ou transformada em novos produtos alimentícios.

\section{FUNDAMENTAÇÃO TEÓRICA}

As hortaliças são plantas cultivadas em campo ou estufas que em sua grande parte são utilizadas como alimento, podem ser classificadas de diferentes formas, uma delas é por parte 


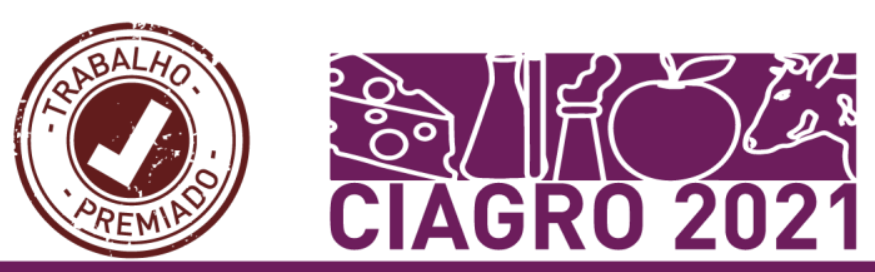

comestível, onde entram as folhas ou hortaliças folhosas como coentro, alface, acelga, couve, salsa entre outras (ABCSEM, 2016). De acordo com Chitarra e Chitarra (2005), hortaliças podem ser definidas como as partes das plantas que não pertencem ao grupo das frutas e cereais e que podem ser consumidas cruas, frescas ou processadas. De maneira geral, as hortaliças podem ser divididas em quatro categorias: sementes e vagens, frutos, bulbos, raízes e tubérculos e folhas, flores e brotos.

A importância da ingestão de hortaliças na alimentação humana está inteiramente voltada para o campo nutricional, visto que este consumo se faz pela precisão de suprir as necessidades nutricionais do organismo, auxiliando na realização de reações orgânicas e hidratando o corpo, evitando que ocorra uma carência nutricional e fragilidade do mesmo. Com isso, a melhor forma de ingerir as hortaliças é em sua forma crua, pois o aquecimento e/ou a forma de preparo pode gerar perda de nutrientes. Na composição das hortaliças é possível encontrar substâncias necessárias para o bom funcionamento do organismo como água, fibras, vitaminas, minerais e componentes antioxidantes. Além disso, são alimentos pobres em calorias, e podem apresentar altos valores de carboidratos, proteínas e lipídeos, dependendo da categoria (RODRIGUES, 2012).

As cores das hortaliças também auxiliam na indicação de sua nutrição, no caso das hortaliças folhosas de cores verdes podem apresentar uma série de nutrientes como: próvitamina A, luteína, vitamina B2, vitamina B5, vitamina B9, vitamina C, vitamina $\mathrm{K}$, cálcio, ferro, magnésio e potássio. E também, segundo Rodrigues (2012) essas hortaliças podem auxiliar no crescimento e na manutenção da pele, ossos, cabelos e visão, contribuem para os sistemas digestivo, nervoso, imunológico e sexual, e podem reduzir o colesterol e o risco de doenças cardiovasculares.

Além das hortaliças folhosas existem as plantas alimentícias não convencionais (PANC) que são plantas ou partes de plantas (talos, cascas, folhas, sementes, flores) seguras e comestíveis, que não fazem parte dos hábitos alimentares humanos. São comumente utilizadas de forma tradicional como alimento e/ou uso medicinal, podendo ser ingerida em diversas formas como chás, sucos, xaropes, cruas, cozidas entre outras (SARTORI et al., 2020).

A serigueleira (Spondias purpurea L.) é uma planta pertencente à família Anarcadiaceae, é uma árvore frutífera, de clima tropical e com grande capacidade de adaptação ao calor e a seca, possui um longo ciclo de vida e geralmente é cultivada em quintais e sítios ou explorada economicamente pelo seu valor comercial (LIMA et al., 2002; MITCHELL; DALY, 1995). As partes da planta como os frutos, as folhas, as sementes e as cascas da serigueleira são utilizadas no uso popular medicinal por apresentarem propriedades terapêuticas antibacterianas, 


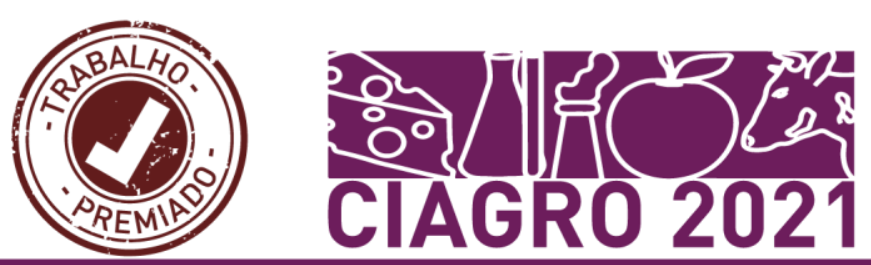

diuréticas, antiespasmódicas e antitérmicas. Além disso, são comumente consumidas em forma

de chás, sucos, xaropes, ensopados ou in natura, como é o caso dos frutos e até mesmo das folhas (Figura 01) (SIGRIST, 2015), dessa forma, as partes da serigueleira podem ser caracterizados como PANCs.

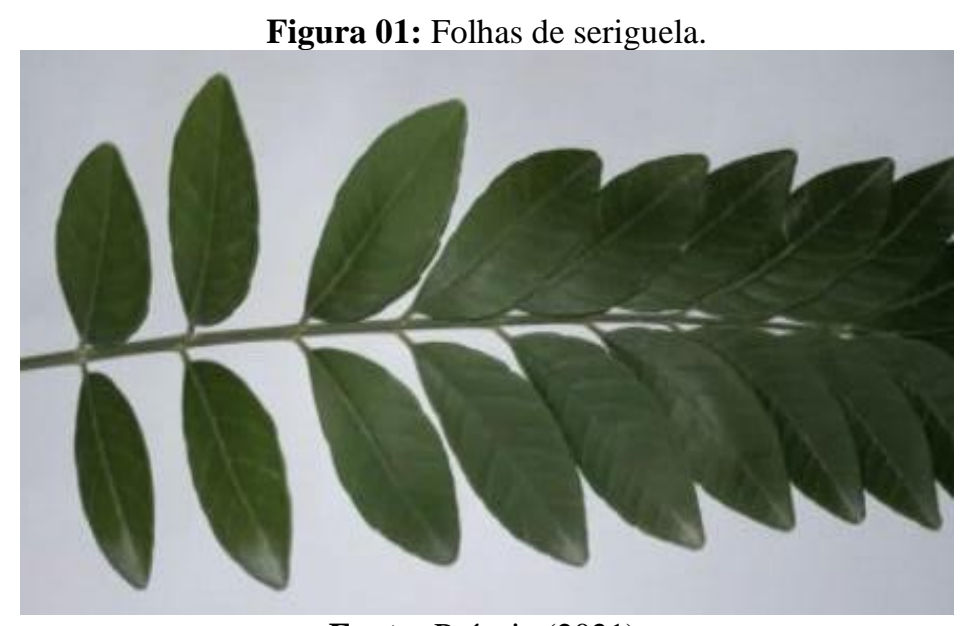

Fonte: Própria (2021).

Devido a versatilidade no uso e no preparo das hortaliças folhosas e das PANCs tornase visível a possibilidade do desenvolvimento de novos produtos alimentícios. Podem ser utilizadas como ingredientes principais ou secundários, agregando ao produto aroma, sabor e valor nutricional, que em algumas PANCs podem ser iguais ou superiores aos encontrados nas hortaliças, raízes e frutas comumente utilizadas nos hábitos alimentares diários da população brasileira. Assim, o uso das PANCs pode constituir como uma importante estratégia para ampliar a oferta de nutrientes à população (FONSECA et al., 2018; TERRA; VIERA, 2019).

As análises físico-químicas de um alimento garantem um detalhamento completo da composição da matéria-prima para fins de pesquisas de novos produtos, fiscalização e controle de qualidade. Desta forma, a determinação da composição físico-química de um alimento informa os parâmetros não visíveis do alimento, que ao serem compatíveis com outros alimentos da mesma categoria ou categoria similar tornam-se possíveis para complementação alimentar ou aplicação em novos produtos alimentícios (MELO FILHO; SILVA; VASCONCELOS, 2013).

Diante disso, a caracterização físico-química das PANCs ressalta os seus benefícios nutricionais, suas propriedades bioativas e suas funções nutracêuticas, ampliando o conhecimento da população em geral e garantindo que outras espécies possam ser descobertas e estudadas. Assim, a partir do conhecimento do seu potencial nutricional e seus efeitos funcionais e medicinais torna-se notável a sua aplicação como fontes complementares de alimentos no desenvolvimento de novos produtos de categoria funcional ou no melhoramento 
das formulações de produtos já existentes, visto que a busca por uma alimentação saudável gera oportunidades para inovações na área de produtos alimentícios (BREDARIOL, 2015; FONSECA et al., 2018; QUEIROZ, 2020).

\section{METODOLOGIA}

\section{MATÉRIA-PRIMA}

As folhas de seriguela foram coletadas na cidade de Lagoa do Ouro-PE e transportadas para a cidade de Garanhuns-PE em embalagem de polietileno à temperatura ambiente de aproximadamente $26^{\circ} \mathrm{C}$, em seguida foram lavadas com água corrente e secas com papel toalha para iniciar a realização das análises físico-químicas.

\section{ANÁLISES FÍSICO-QUÍMICAS}

Foram realizadas as análises físico-químicas de teor de umidade, teor de cinzas, cor, pH, sólidos solúveis totais (SST), atividade de água (Aw), acidez total titulável (ATT), açúcares redutores e lipídeos. Todas as análises realizadas foram realizadas em triplicata e baseadas nas normas analíticas do Instituto Adolfo Lutz (2008).

\section{Teor de umidade}

Foi adicionado $2 \mathrm{~g}$ a $10 \mathrm{~g}$ da amostra em um cadinho de porcelana previamente tarado e em seguida levado à estufa por 30 minutos a $105^{\circ} \mathrm{C}$. Após isso, foi resfriado em um dessecador até atingir a temperatura ambiente de $26^{\circ} \mathrm{C}$ e, pesado. Esse procedimento foi repetido até as amostras atingirem peso constante, ao atingirem este ponto, foi calculada a diferença de massa antes e depois do aquecimento. O cálculo do percentual de umidade foi avaliado conforme a Equação 1.

Umidade $\%=\frac{100 * N}{P}$

Onde:

$\mathrm{N}$ - Diferença de massa da amostra inicial e final em gramas.

P - Número de gramas da amostra inicial. 
Após a análise de teor de umidade a amostra foi levada à mufla a $550{ }^{\circ} \mathrm{C}$ por 1 hora até a incineração completa da matéria orgânica, o resíduo restante de coloração cinza ou cinza esbranquiçada representa a matéria inorgânica proveniente das cinzas. O resíduo obtido após o procedimento foi pesado e utilizado para calcular o percentual de cinzas conforme a Equação 2.

Cinzas $\%=\frac{100 * \mathrm{~N}}{\mathrm{P}}$

Onde:

$\mathrm{N}$ - Número de gramas final, ou seja, massa de cinza em gramas.

P - Número de gramas da amostra inicial.

\section{Cor}

A análise de cor foi realizada utilizando um colorímetro portátil manual Konica MINOLTA CR-10, que indica os parâmetros $L^{*}$ para luminosidade $(0 \%=$ escuro e $100 \%=$ branco), coordenada cromática $a^{*}$ (componente $(+)$ vermelho e (-) verde) e coordenada cromática $b^{*}$ (componente (+) amarelo e (-) azul).

pH

$\mathrm{O} \mathrm{pH}$ foi indicado utilizando um pHmetro digital de bancada (precisão $\pm 0,01 \mathrm{pH}$, MARCONI, PA200) previamente calibrado. Em um béquer de $200 \mathrm{~mL}$ previamente tarado foi pesado $50 \mathrm{~g}$ da amostra que foi macerada até a liberação do sumo das folhas de seriguela, 10 $\mathrm{mL}$ desse líquido extraído da amostra foi adicionado a $100 \mathrm{~mL}$ de água destilada formando uma solução que foi utilizada para medir o $\mathrm{pH}$ da amostra.

\section{Sólidos solúveis totais}

A solução obtida para a análise de $\mathrm{pH}$ foi utilizada para realizar a análise de sólidos solúveis totais (SST). Em um refratômetro portátil digital da marca Homis modelo HRE-32k foi pipetado uma gota da solução, o resultado foi expresso em graus Brix que, em seguida foi convertido para porcentagem de sólidos solúveis totais. 
A atividade de água (Aw) foi determinada utilizando o analisador de atividade de água Aqualab previamente calibrado. Em um béquer de $50 \mathrm{~mL}$ foi pesado $10 \mathrm{~g}$ da amostra e em seguida macerada, após isso, foi transferida para o recipiente de plástico do equipamento e colocada para leitura por cerca de 20 minutos, o resultado foi expresso em aw.

\section{Acidez total titulável}

A análise de acidez total titulável (ATT) foi realizada por meio de titulação com hidróxido de sódio $(\mathrm{NaOH})$ a $0,1 \mathrm{~N}$. Em um béquer de $100 \mathrm{~mL}$ previamente tarado foi pesado $50 \mathrm{~g}$ da amostra que foi macerada até a liberação do sumo das folhas de seriguela, $10 \mathrm{~mL}$ desse líquido extraído da amostra foi filtrado e transferido para um erlenmeyer de $125 \mathrm{~mL}$ onde foi adicionado a $50 \mathrm{~mL}$ de água destilada e 2 gotas da solução de fenolftaleína, esta solução foi titulada até o ponto de viragem que apresentou coloração puxada para a tonalidade marrom. $\mathrm{O}$ cálculo para obtenção do valor de ATT foi realizado através da Equação 3 e o resultado foi expresso em acidez em solução molar por cento $\mathrm{v} / \mathrm{m}$.

Acidez $=\frac{\mathrm{V} * \mathrm{f} * 100}{\mathrm{P} * \mathrm{c}}$

Onde:

V - Número de mL da solução de hidróxido de sódio 0,1 N gasto na titulação.

f - Fator da solução de hidróxido de sódio $0,1 \mathrm{~N}$.

P - Número de gramas da amostra utilizada na titulação.

c - Correção para solução de $\mathrm{NaOH} 0,1 \mathrm{~N}$.

\section{Açúcares Redutores}

Para a determinação de açúcares redutores foi utilizado um béquer de $100 \mathrm{~mL}$ previamente tarado onde foi pesado $50 \mathrm{~g}$ da amostra e macerada até a liberação do sumo das folhas de seriguela, $5 \mathrm{~mL}$ desse líquido extraído da amostra foi transferido para um béquer de $100 \mathrm{~mL}$ onde foi adicionado $50 \mathrm{~mL}$ de água destilada e em seguida filtrado. Após isso, pipetouse $2 \mathrm{~mL}$ dessa solução em um tubo de ensaio com $1 \mathrm{~mL}$ do reagente ácido 3,5:dinitro salicilato (DNS). Em seguida, o tubo de ensaio foi submetido em banho-maria a $100{ }^{\circ} \mathrm{C}$ por 5 minutos e 

$\mathrm{nm}$, onde os resultados foram expressos em porcentagem.

\section{Lipídeos}

Para determinação de lipídeos empregou-se o método de extração por Soxhlet. Foi pesado $1 \mathrm{~g}$ da amostra em um papel de filtro e em seguida amarrado com fio de lã previamente desengordurado. O papel de filtro amarrado foi transferido para o aparelho extrator tipo Soxhlet onde foi acoplado o extrator ao balão de fundo chato previamente tarado a $105{ }^{\circ} \mathrm{C}$. Foi adicionado n-hexano e iniciado o aquecimento até a ebulição, a extração durou aproximadamente 2 horas totalizando 5 viragens para cada extrator. Ao final da extração foi retirado o papel de filtro amarrado e levado à estufa por 1 hora a $105{ }^{\circ} \mathrm{C}$, em seguida foi submetido ao dessecador até atingir a temperatura ambiente e, posteriormente, pesado para obter-se a massa de gordura presente na amostra. O resultado do percentual de lipídeos foi obtido através da Equação 4.

Lipídeos $\%=\frac{100 * \mathrm{~N}}{\mathrm{P}}$

Onde:

N - Número de gramas de lipídeos.

P - Número de gramas da amostra inicial.

\section{RESULTADOS E DISCUSSÃO}

A composição físico-química da folha de seriguela foi determinada pelos valores obtidos de teor de umidade, teor de cinzas, pH, SST, Aw, ATT, açúcares redutores e lipídeos, apresentados na Tabela 01. As análises foram realizadas em triplicata à temperatura ambiente de $28,8^{\circ} \mathrm{C}$ e os resultados representam a média dos experimentos e o desvio padrão calculados no Excel. 


\begin{tabular}{cc}
\hline Análise Físico-química & Média \pm Desvio \\
\hline Teor de umidade $(\%)$ & $30,34 \pm 2,16$ \\
Teor de Cinzas $(\%)$ & $3,51 \pm 0,14$ \\
$\mathrm{~L}^{*}($ Luminosidade) & $46,27 \pm 0,63$ \\
$\mathrm{a}^{*}($ componente vermelho-verde) & $-12,33 \pm 0,39$ \\
$\mathrm{~b}^{*}$ (componente amarelo-azul) & $+29,80 \pm 0,73$ \\
pH & $2,39 \pm 0,01$ \\
Sólidos Solúveis Totais ( ${ }^{\circ}$ Brix) & $9,73 \pm 0,09$ \\
Atividade de Água (aw) & $0,99 \pm 0,00$ \\
Acidez Total Titulável (\%) & $0,13 \pm 0,00$ \\
Açúcares Redutores (g/L) & $0,835 \pm 0,01$ \\
Lipídeos (\%) & $6,56 \pm 0,12$ \\
\hline
\end{tabular}

Fonte: Própria (2021).

O teor de umidade das folhas de seriguela foi de $30,34 \%$, sendo um valor muito baixo quando comparado com os teores de umidade de outras folhas alimentícias como as folhas de manjericão (72,39\%) (FERREIRA; SILVEIRA JÚNIOR, 1999), as folha de amora $(63,67 \%)$ (PORTO; COSTA, 2010), as folhas de acelga (97,89\%), folhas de alface $(95,81 \%)$ e folhas de couve (91,58\%) (PEREIRA et al., 2016). Esse resultado pode estar associado a região de origem da planta matriz onde foram coletadas as amostras, pois esta espécie é especificamente de zonas tropicais com solos de baixa umidade (PORTAL SÃO FRANCISCO, 2018). Segundo Araújo (2010) o teor de umidade em vegetais está diretamente relacionado a sua absorção de água, então o baixo teor de umidade das folhas de seriguela pode ser explicado pela localização da árvore de amostragem, no município de Lagoa do Ouro-PE, região do agreste meridional de Pernambuco, local de clima predominante semi-árido e baixa umidade.

De acordo com Cecchi (2003), as cinzas de um alimento são resíduos inorgânicos que permanecem após a queima da matéria orgânica, esta, por sua vez é transformada em $\mathrm{CO}_{2}, \mathrm{H}_{2} \mathrm{O}$ e $\mathrm{NO}_{2}$. A quantidade de materiais inorgânicos presente nas amostras foi identificada a partir da mudança na coloração das amostras, de verde escuro para totalmente branca, essa mudança de coloração representa a queima de todos os compostos orgânicos presentes na amostra. $\mathrm{O}$ teor de cinzas das folhas de seriguela foi $3,51 \%$, esse valor está relativamente próximo ao teor de cinzas em folhas comestíveis como as folhas de alface $(1,35 \%)$ e folhas de couve $(1,61 \%)$ (PEREIRA et al., 2016). Estes compostos são resíduos minerais fixos como sódio, potássio, magnésio, cálcio, ferro, fósforo, cobre, cloreto, alumínio, zinco, manganês e outros compostos 


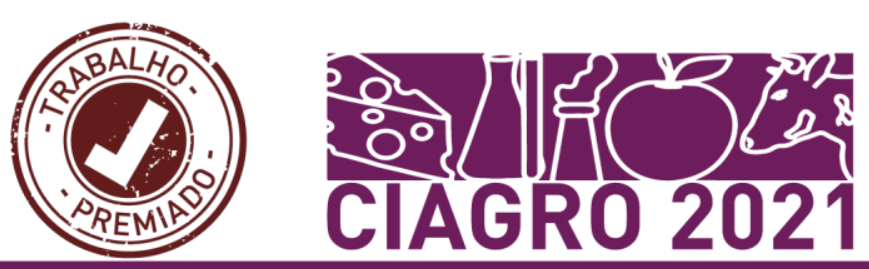

minerais remanescente da queima da matéria orgânica em mufla a altas temperaturas (500 $\left.600{ }^{\circ} \mathrm{C}\right)($ ZAMBIAZI, 2010).

O parâmetro de cor foi verificado para a amostra in natura recém coletada que apresentou índices de tonalidade verde e amarelo indicadas pelas coordenadas cromáticas negativas de $a^{*}(-12,33)$ e positivas de $b^{*}(+29,80)$ e uma boa luminosidade indicada em $L^{*}$ (46,27), esses dados coincidem com sua aparência de folha verde.

A folha de seriguela apresentou $\mathrm{pH}$ 2,39, sendo um valor muito baixo quando comparado com valores de $\mathrm{pH}$ de outras folhas comestíveis como a folha da moringa oleífera desidratada ( $\mathrm{pH} 5,49)$ (PEDRAL et al., 2015) e as folhas de hortaliças folhosas como acelga ( $\mathrm{pH} 5,62)$, alface ( $\mathrm{pH} 5,97)$ e couve ( $\mathrm{pH} 5,56)$ (PEREIRA et al., 2016). Esse valor resulta em um pH muito ácido, sendo demonstrado pelo sabor amargo ao ser consumido.

O teor de sólidos solúveis totais presentes na folha de seriguela foi de $9,73{ }^{\circ}$ Brix, tornando-se um valor bastante elevado quando comparado com os valores de SST das hortaliças folhosas acelga, alface e couve, que é de 1,23, 1,60 e 4,16 ( ${ }^{\circ}$ Brix) respectivamente (PEREIRA et al., 2016). Quando foi avaliado o teor de SST da fruta de seriguela madura e da fruta "verde" obteve-se 11,56 e 10,30 ${ }^{\circ}$ Brix, respectivamente, sendo valores bem próximos do encontrado para a folha. Desta forma, o elevado valor de SST da folha de seriguela pode ter relação com alguns ácidos orgânicos que ficam dispersos no suco celular, e consequentemente estes são computados como sólidos solúveis para a folha (PEREIRA et al., 2016), tendo em vista que a análise de SST foi realizada com a solução do sumo não filtrado da folha.

O valor de atividade de água da folha de seriguela in natura foi de 0,99 aw, sendo um valor de atividade de água próximo aos de folhas e ervas comestíveis in natura como manjericão (0,97 aw), coentro (0,97 aw), alecrim (0,96 aw) e salsa (0,98 aw) (SILVA, 2018). Esse resultado pode ser justificado pela influência do clima semi-árido na árvore de amostragem, forçando a planta a reter água nas folhas para evitar a evaporação total em períodos prolongados sem chuvas.

A acidez total titulável da folha de seriguela foi de 0,13 de acidez em solução molar por cento $\mathrm{v} / \mathrm{m}$, sendo um valor próximo ao encontrado em outras folhas e hortaliças como a folha de moringa oleífera desidratada que apresenta ATT na faixa de 0,02-0,37\% (PEDRAL et al., 2015) e das hortaliças folhosas acelga, alface e couve como uma faixa de ATT de 0,08\%, 0,07\% e $0,30 \%$, respectivamente (PEREIRA et al., 2016).

Os valores de açúcares redutores como a glicose e a frutose estão diretamente relacionados ao processo de sintetização realizado pelas folhas das plantas através do floema, esses açúcares se translocam durante o dia e a noite em todas as partes da planta, alimentando 


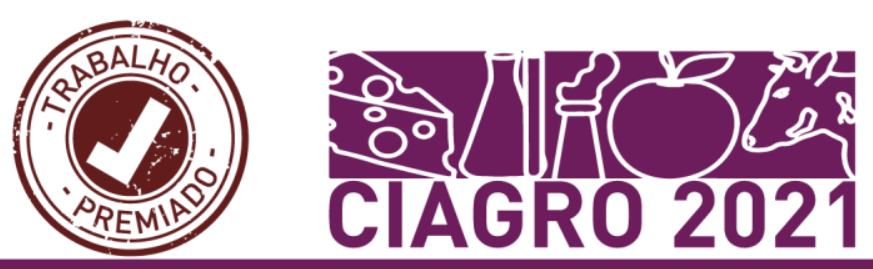

o desenvolvimento da inflorescência (SOUZA et al., 2013). A quantidade de açúcares redutores presente nas folhas de seriguela foi de $0,835 \mathrm{~g} / \mathrm{L}$ e apresentou equivalência quando comparado às folhas e flores de brócolis cru (1,060 g/L) (PIGOLI, 2012).

O teor lipídico das folhas de seriguela foi de 6,56\%, tornando-se um valor alto quando comparado com outras folhas comestíveis como alecrim-pimenta $(1,04 \%)$, alfavaca $(1,44 \%)$ e mostarda (2,42\%) (ALMEIDA et al., 2003), porém, demonstram uma equivalência comparado com outras folhas comumente utilizadas para o preparo de chás como as folhas de sabugueiro $(6,26 \%)$ e folhas de maracujá $(8,19 \%)$ (ALMEIDA et al., 2003). Dessa forma, a proximidade dos teores lipídicos das folhas de seriguela e de sabugueiro pode ser justificada pela região de origem dessas plantas, zonas tropicais e de baixa umidade.

Apesar das diversas formas de consumo das folhas de seriguela pelo senso comum de algumas pessoas, se faz necessário a realização de testes de toxicidade em espécies não convencionais ou exóticas, para que seja possível determinar o comportamento toxicológico da mesma quando adicionada ou transformada em um produto e/ou subproduto alimentício, garantindo maior segurança alimentar para o consumidor (LUIZ, 2016).

Para a determinação da composição centesimal é recomendado que sejam realizadas outras análises, como carboidratos e fibras, pois, os carboidratos garantem volume e corpo aos produtos alimentícios e são amplamente disponíveis e de baixo custo e as fibras são nutricionalmente importantes, uma vez que atuam na regulação e no funcionamento do trato gastrointestinal e garantem uma ação funcional ao alimento (MANGOBA, 2015).

Os dados referentes às análises físico-químicas realizadas para as folhas de seriguela indicam, em sua maioria, que as mesmas apresentam parâmetros semelhantes a outras folhas, hortaliças folhosas e PANCs comumente consumidas pela população brasileira, firmando a possibilidade do desenvolvimento de novos produtos alimentícios tendo as mesmas como ingredientes (QUEIROZ, 2020; TERRA; VIEIRA, 2019).

Portanto, a composição nutricional e centesimal das folhas de seriguela podem indicar suas possíveis aplicações nas formulações para melhoramento de produtos já existentes ou no desenvolvimento de novos produtos alimentícios de categoria funcional, e assim como as folhas de ora-pro-nóbis, podem ser aplicadas em diversas preparações como: saladas, refogados, farinhas, tortas, massas alimentícias, sucos, geleias, licores, medicamentos fitoterápicos e doces, como paçocas e balas (QUEIROZ, 2020; ROMANO et al., 2017). 
Deste modo o presente trabalho realizou a caracterização física e química das folha de seriguela, determinando os parâmetros de teor de umidade, teor de cinza, cor, pH, sólidos solúveis totais, atividade de água, acidez total titulável, açúcares redutores e lipídeos.

O resultado obtido para o teor de umidade está abaixo do percentual encontrado para outras folhas comestíveis. Entretanto, os valores obtidos para o teor de cinzas, atividade de água, acidez total titulável, açúcares redutores e lipídeos encontram-se próximos dos dados utilizados como referência para folhas, ervas e hortaliças folhosas comestíveis.

O resultado obtido para sólidos solúveis totais se enquadrou com o valor de ${ }^{\circ}$ Brix para a fruta seriguela, estando relativamente alto quando comparado com outras folhas comestíveis. $\mathrm{O} \mathrm{pH}$ da folha de seriguela demonstrou-se mais ácido do que o $\mathrm{pH}$ relatado para hortaliças folhosas comestíveis e a cor apresentou equivalência para as tonalidades descritas para folhas frescas comestíveis.

Sendo assim, as folhas de seriguela podem ser adicionadas ou transformadas em alimentos, podendo ser uma alternativa viável para o desenvolvimento de novos produtos alimentícios visto que sua composição apresenta as características físico-químicas referentes ao teor de cinzas, cor, atividade de água, acidez total titulável, açúcares redutores e lipídeos muito próximas da faixa desejável para folhas, flores e hortaliças folhosas, comumente utilizadas em alimentos como saladas, chás e sucos.

Portanto, é notável o potencial nutricional, funcional e nutracêutico das folhas de seriguela, sendo necessário que sejam realizados outros estudos para confirmar as suas possíveis aplicabilidades nas formulações de alimentos já existentes ou no desenvolvimento de novos produtos alimentícios como: saladas, refogados, farinhas, temperos, tortas, massas alimentícias, sucos, geléias, licores, chás e doces.

\section{REFERÊNCIAS}

ABCSEM. Associação Brasileira do Comércio de Sementes e Mudas. O mercado de folhosas: números e tendências. Seminário Nacional, Campinas-SP. 2016. Disponível em:https://www.abcsem.com.br/upload/arquivos/O_mercado_de_folhosas_Numeros_e_Ten dencias___Steven.pdf . Acesso em: 06 abr. 2021. 
ALMEIDA, M. E. F.; JUNQUEIRA, A. M. B.; SIMÃO, A. A.; CORRÊA, A. D. Caracterização química das hortaliças não-convencionais conhecidas como ora-pro-nóbis. Bioscience Journal, v. 30, n. 1, p. 431-439, 2014.

ALMEIDA, M. M. B; LOPES, M. F. G; SOUZA, P. H. M; NOGUEIRA, C. M. D; MAGALHÃES, C. E. C. Determinação de umidade, fibras, lipídeos, cinzas e sílica em plantas medicinais. Boletim do Centro de Pesquisa de Processamento de Alimentos, v. 21, n. 2, p. 343-350, 2003.

ARAÚJO, A. C. Determinação de teor de umidade. 2010. 4f. Relatório de Pesquisa (Bioquímica Vegetal) - Departamento de Química, Universidade Federal Rural de Pernambuco, Recife, 2010.

BREDARIOL, L. R. Levantamento e caracterização das Plantas Alimentícias Não Convencionais (PANC'S) espontâneas presentes em um Sistema Agroflorestal no município de Rio Claro - SP. 2015. 44f. Trabalho de Conclusão de Curso (Graduação em Ecologia) - Instituto de Biociências, Universidade Estadual Paulista "Júlio de Mesquita Filho", Rio Claro, 2015.

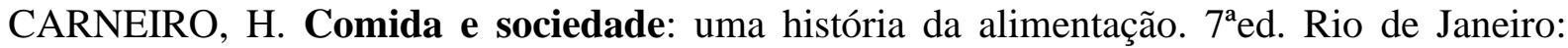
Editora Elsevier, 2003.

CECCHI, H. M. Fundamentos teóricos e práticos em análise de alimentos. $2^{\mathrm{a}} \mathrm{ed}$. Campinas: Editora UNICAMP, 2003.

CHITARRA, M. I, F.; CHITARRA, A. B. Pós-colheita de frutas e hortaliças: fisiologia e

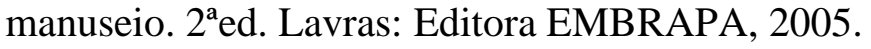

DIAS, A. C. P.; PINTO, N. A. V. D.; YAMADA, L. T. P.; MENDES, K. L.; FERNANDES, A. G. Avaliação do consumo de hortaliças não convencionais pelos usuários das unidades do programa saúde da família (PSF) de Diamantina - MG. Revista Alimentos e Nutrição, v. 16, n. 3, p. 29-284, 2005.

FERREIRA, F. C; SILVEIRA JÚNIOR, V. Secagem a vácuo a diferentes pressões: avaliações físicas e sensoriais de manjericão. Revista Brasileira de Produtos Agroindustriais, v.1, n.1, p. 59-65, 1999.

FONSECA, C.; LOVATTO, P.; SCHIEDECK, G.; HELlWIG, L.; GUEDES, A. F. A importância das Plantas Alimentícias Não Convencionais (PANCS) para a sustentabilidade dos sistemas de produção de base ecológica. In: VI CONGRESSO LATINO-AMERICANO, X CONGRESSO BRASILEIRO e V SEMINÁRIO DO DF E ENTORNO, 1., 2018, Brasília. Anais [...], Brasília: Cadernos de Agroecologia, v. 13, n. 1, 2018. p. 1-7.

FREIRE, G. Açúcar: em torno da etnografia, da história e da sociologia do doce no Nordeste Brasileiro. $3^{\text {a }}$ ed. Recife: Editora Massangana, 1987.

INSTITUTO ADOLFO LUTZ. Métodos físico-químicos para análise de alimentos. $4^{\mathrm{a} e d}$. São Paulo: Editora Instituto Adolfo Lutz, 2008. 


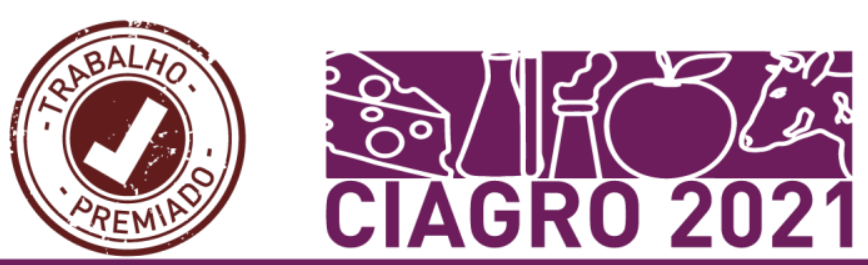

LIMA, A. K. C.; REZENDE, L. P.; CÂMARA, F. A. A.; NUNES, G. H. S. Propagação de cajarana (Spondias sp.) e ciriguela (Spondias purpurea) por meio de estacas verdes enfolhadas, nas condições climáticas de Mossoró-RN. Revista Caatinga, v. 15, n. 1-2, p. 33-38, 2002.

LUIZ, C. G. G. Avaliação da segurança alimentar do extrato de frutos do Jaracatiá spinosa: ensaios toxicológicos em camundongos. 2016. 90f. Dissertação (Mestrado em Segurança Alimentar e Nutricional) - Setor de Ciências da Saúde, Universidade Federal do Paraná, Curitiba, 2016.

MANGOBA, P. M. A. Prospecção de características fitoquímicas, antibacterianas e físicoquímicas de Portulaca oleracea L. (Beldroega). 2015. 84f. Dissertação (Mestrado em Ciência e Tecnologia de Alimentos) - Instituto de Ciência e Tecnologia de Alimentos, Universidade Federal do Rio Grande do Sul, Porto Alegre, 2015.

MELO FILHO, A. B.; SILVA, A. M. A. D.; VASCONCELOS, M. A. S. Análises físicoquímicas dos alimentos. Recife: Editora EDUFRPE, 2013.

MITCHELL, J. D.; DALY, D. C. Revisão das espécies neotropicais de Spondias (Anacardiaceae). In: CONGRESSO NACIONAL DE BOTÂNICA, 46., 1995, São Paulo. Anais [...], São Paulo: USP, 1995. p. 207.

PEDRAL, A. L.; BARBOSA, J. S.; SANTOS, G. R.; XAVIER, A. C. R.; ARIMATÉA, C. C.; FONTES, A. S.; SILVA, G. F.; BARRETTO, L. C. O. Caracterização físico-química de folhas da moringa oleífera desidratadas por secagem convectiva e liofilização. Revista Brasileira de Produtos Agroindustriais, v. 17, n. 1, p. 33-39, 2015.

PEREIRA, E. M.; LEITE, D. D. F.; FIDELIS, V. R. L.; PORTO, R. M.; OLIVEIRA, M. I. V.; MAGALHÃES, W. B. Caracterização físico-química de hortaliças tipo folha comercializadas no Brejo Paraibano. Revista Agropecuária Técnica, v. 37, n. 1, p. 19-22, 2016.

PIGOLI, D. R. Alterações nutricionais em hortaliças decorrentes de diferentes métodos de cozimento. 2012. 64f. Dissertação (Mestrado em Agronomia, Energia na Agricultura) Faculdade de Ciências Agronômicas, Universidade Estadual Paulista "Júlio de Mesquita Filho", Botucatu, 2012.

PORTAL SÃO FRANCISCO: Seriguela. 2018 Disponível em: https://www.portalsaofrancisco.com.br/alimentos/siriguela. Acesso em: 06 abr. 2021.

PORTO, A. J; COSTA, C. Umidade na folha de amoreira (Morus sp.) em ambientes de armazenamento. Boletim de Indústria Animal, v. 67, n. 2, p. 183-189, 2010.

QUEIROZ, T. L. Desenvolvimento e análise físico-química de paçoca de amendoim e castanha de caju adicionada de ora-pro-nóbis (Pereskia aculeata Miller). 2020. 46f. Trabalho de Conclusão de Curso (Bacharelado em Nutrição) - Unidade Acadêmica de Saúde, Universidade Federal de Campina Grande, Cuité, 2020.

RAMALHO, R. A.; SAUNDERS, C. O papel da educação nutricional no combate às carências nutricionais. Revista de Nutrição, v. 13, n. 1, p.11-16, 2000.

RODRIGUES, P. A importância nutricional das hortaliças. Revista Embrapa Hortaliças, v. 1, n. 2, p. 6-9, 2012. 


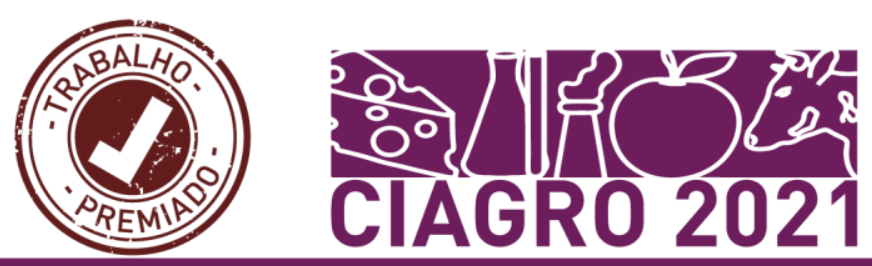

ROMANO, B. C.; MÉLLO, M. H. G.; MELO, F. R. G.; BRONZI, E. S.; AREVABINI, C. A.

M. Desenvolvimento de bala de ora-pro-nóbis: uma alternativa para o consumo de nutrientes.

Revista Científica Linguagem Acadêmica: Dossiê Nutrição, v. 7, n. 5, p. 57-66, 2017.

SARTORI, V. C.; THEODORO, H.; MINELLO, L. V.; PANSERA, M. R.; BASSO, A.; SCUR, L. Plantas Alimentícias Não Convencionais - PANC: resgatando a soberania alimentar e nutricional. Caxias do Sul: Editora EDUCS, 2020.

SIGRIST, S. Seriguela. Portal de Plantas Medicinais, Aromáticas e Condimentares (PPMAC). Disponível em:https://www.ppmac.org/content/seriguela. Acesso em: 10 abr. 2021.

SILVA, J. A. S. L. Desidratação de ervas condimentares: análise do processo de secagem. 2018. 44f. Trabalho de Conclusão de Curso (Bacharelado em Nutrição) - Centro Acadêmico de Vitória, Universidade Federal de Pernambuco, Vitória de Santo Antão, 2018.

SOUZA, E. R; RIBEIRO, V. G.; DANTAS, B. F.; LIMA FILHO, J. M. P. Variação de carboidratos em folhas da videira 'Itália' submetida a diferentes de níveis de desfolhas. Revista Brasileira de Ciências Agrárias, v. 8, n. 4, p. 535-539, 2013.

TERRA, S. B.; VIERA, C. T. R. Plantas Alimentícias Não Convencionais (PANCs): levantamento em zonas urbanas de Santana do Livramento, RS. Revista Ambiência, v. 15, n. 1, p. 112 - 130, 2019.

ZAMBIAZI, R. C. Análise físico-química de alimentos. Pelotas: Editora UFPEL, 2010. 